\title{
"Apesar de vocês amanhã vai ser outro dia" \\ Imprensa alternativa versus ditadura militar em Porto Alegre
}

\author{
Susel Oliveira da Rosa*
}

\begin{abstract}
Resumo: Considerando a importância da imprensa alternativa durante os anos da ditadura militar no Brasil, inicialmente apresento algumas considerações acerca das características dessa imprensa, que sustentou um discurso de oposição e resistência às diversas facetas do autoritarismo. A partir daí escrevo sobre a trajetória de três jornais alternativos que circularam em Porto Alegre na época: Exemplar, Pato Macho e Coojornal.
\end{abstract}

Palavras-chave: Imprensa alternativa; Ditadura militar; Porto Alegre.

\begin{abstract}
Considering the importance of the alternative press during the years of the military dictatorship in Brazil, I initially present some observations regarding the features of such press, which kept a speech of opposition and resistance regarding several aspects of authoritarianism. In this context I write about the path of three alternative newspapers issued in Porto Alegre at the time: Exemplar, Pato Macho, and Coojornal.
\end{abstract}

Keywords: Alternative press, Military dictatorship, Porto Alegre.

\section{A oposição possível}

"fui para a oposição possível e fiz o caminho possível, que no meu entender não era a luta armada, nem a clandestinidade, mas o humor armado..."1

Quando falamos em imprensa alternativa, logo vem à mente jornais como Pasquim, Opinião, Movimento, Lampião da Esquina, Em Tempo, Brasil Mulher, Beijo, Ex, Versus. Esses são alguns dentre os muitos jornais alternativos que circularam entre os anos de 1964 a 1984 no Brasil, e que ousaram romper com o silêncio que recaía sobre a grande imprensa.

\footnotetext{
* Susel Oliveira da Rosa é mestre em História das Sociedades Ibéricas e Americanas pela PUCRS e, atualmente, doutoranda em História na UNICAMP. O artigo aqui publicado é oriundo de seu trabalho de mestrado, que trata da trajetória da imprensa alternativa em Porto Alegre. Sua última publicação é "Violência e ordem: Porto Alegre das décadas de 70, 80 e 90", na Revista CCSH do CCSH/UFSM e "Dromologia, Tempo e História". In: Foucault Perspectivas: 2004. [Florianópolis]: UFSC/Udesc, p. 943-948. 1 CD-ROM

${ }^{1}$ Citação de Henfil ao falar de seu trabalho nos jornais alternativos.
} 
Eram jornais de pequeno porte que agrupavam jornalistas, intelectuais, estudantes universitários, políticos afastados pelo regime. Pessoas que buscavam espaço para expor suas idéias, já que, na grande imprensa, estes espaços haviam sido fechados pela censura e pela autocensura. Muitos desses jornais alternativos já nasciam censurados, enquanto outros não chegavam a sofrer censura direta. Atuação censória essa que só pode ser compreendida se considerarmos seu caráter multifacetado que, dependendo das características do veículo de comunicação (público-leitor, alcance, forma de divulgação, tiragem, entre outros) incidia ou não. A censura atuava de forma mais ou menos rigorosa, não tendo, portanto, uma atuação homogênea. Em alguns órgãos foi uma censura política, em outros, econômica, e, por vezes, até pessoal.

Mais de 150 periódicos alternativos foram publicados entre os anos de 1964 a 1984. Abrigando temáticas diversas (políticos, de humor, feministas, homossexuais, culturais), podemos reconhecê-los pela postura de "oposição intransigente ao regime militar" (KUCINSKI, 1991, p.10). São chamados de alternativos, porque a terminologia - alternativo - remete à idéia de resistência contracultural em sentido amplo, ao que não está ligado às políticas dominantes e, também, a uma saída para uma situação difícil.

A invenção da imprensa alternativa remonta aos pasquins do período regencial (18311840) e também aos jornais anarquistas publicados pelos operários entre os anos de 1880 e 1920. A influência mais direta foi do jornal Binômio: um pequeno jornal publicado em Belo Horizonte a partir de 1952, cujo nome fazia referência ao slogan político de Juscelino Kubitschek, "binômio energia-transporte", amplamente divulgado pela imprensa da época. Esse pequeno jornal fez muito sucesso em Minas Gerais, e só deixou de ser editado depois do golpe militar, quando o editor do Binômio precisou fugir do país.

As publicações dos jornais alternativos surgiam na medida em que o espaço para a crítica se fechava cada vez mais na grande imprensa, fazendo com que intelectuais e jornalistas se unissem em torno dos projetos alternativos. Projetos que muitas vezes não ultrapassavam os primeiros números ${ }^{2}$ - duravam algum tempo, sofrendo com as ações da censura, as sanções econômicas, os desentendimentos e as saídas de jornalistas. Entretanto, mesmo por um curto período de tempo, esses jornais conseguiam se manter basicamente sustentados pela vontade de reagir, de escrever o que não se podia dizer na grande imprensa, de ter liberdade de crítica sempre que fosse possível burlar a censura. Diferentemente da imprensa tradicional, os alternativos adotavam uma estrutura de democracia interna, nos

\footnotetext{
${ }^{2}$ Dos mais de 150 jornais alternativos publicados na época, segundo Kucinski, um em cada dois não chegava a completar um ano de existência.
} 
conselhos de redação, na distribuição igualitária no peso dos votos. Na maior parte dos casos representavam sociedades anônimas, companhias limitadas, ou cooperativas. A organização financeira desses jornais desprezava a perspectiva do lucro - que raramente ocorria - pois, na maioria das vezes eles davam prejuízo. Porém, em alguns casos, como aconteceu com o Pasquim, quando havia lucro, esse lucro não era reaplicado, já que a equipe não concordava com o sistema de acumulação capitalista.

Para Kucinski, existiram basicamente duas correntes de jornais alternativos: aqueles que privilegiavam o discurso político e aqueles desvinculados do discurso ideológico. Aqueles que privilegiavam o discurso político geralmente não faziam uso das entrelinhas, sempre que conseguiam publicavam matérias diretas, denunciando os abusos do regime. Já aqueles 'cansados do discurso ideológico' atacavam o autoritarismo através das críticas que giravam em torno dos costumes e do moralismo dos setores médios ${ }^{3}$, inspirados pelos movimentos de contracultura norte-americanos e pelo existencialismo.

Além dessas duas grandes correntes alternativas, surgiram, ainda, alternativos identificados com o novo jornalismo americano da década de 60. As narrativas desses jornais aproximavam-se dos aspectos literários e do jornalismo narrativo, entre eles estavam Bondinho, Ex e Versus. Podemos citar também os alternativos "que procuravam novas categorias explicativas da vida e dos conflitos humanos, que ousaram desafiar a moral pudica dos marxistas ao abrir a discussão sobre a homossexualidade e o prazer" (KUCINSKI, 1999, p.181). Entre esses jornais estavam Lampião da Esquina, dirigido por Aguinaldo Silva, que discutia abertamente a homossexualidade; Mulherio, Brasil Mulher e Nós Mulheres, inspirados nos textos de Simone de Beauvoir e nos movimentos feministas franceses. Lampião, Mulherio, Brasil Mulher e Nós Mulheres, entre outros, trouxeram a discussão da relação de dominação masculina para o seio do discurso marxista de luta política.

Políticos, culturais, literários, humorísticos, todos os alternativos, de uma maneira ou de outra, sofreram, foram cerceados e vigiados pelo regime militar. Um documento do Centro de Informações do Exército ${ }^{4}$ (CIEX) sobre a imprensa alternativa comprova, com o carimbo militar, essa vigilância. No referido documento, além de uma 'gênese' dos jornais alternativos - com classificação e indicação de surgimento de cada um - encontramos 'receitas' para acabar com estes. Dentre elas, a mais popular e indicada eram as sanções econômicas, que

\footnotetext{
${ }^{3}$ Em seu trabalho sobre o Pasquim, Rego (1996, p. 37) afirma que os jornalistas conheciam os grandes defeitos da classe média brasileira porque a ela pertenciam.

${ }^{4} \mathrm{O}$ documento do Centro de Informações do Exército sobre a Imprensa alternativa consta em sua íntegra (anexo 1) no livro de Sérgio Caparelli, Comunicação de Massa sem Massa.
} 
além de não configurarem claramente restrições à liberdade de pensamento, afetavam diretamente os jornais alternativos, que se mantinham com verbas escassas.

Somando-se às sanções econômicas, depois que a censura prévia à imprensa foi oficialmente retirada, já no final da década de 70, no período de 'abertura', os jornais alternativos passaram a conviver com os atentados, com as bombas que eram explodidas em suas redações ou nas bancas que vendiam alternativos. Atentados que eram atribuídos pelo governo a 'terroristas', perpetrados pelos 'terroristas' dos órgãos de segurança e repressão, ou mesmo a mando dos chefes militares e civis do governo.

Os atentados ${ }^{5}$ desestruturaram esses pequenos grandes jornais - muitos deles não conseguiram se reerguer. A atuação terrorista dos órgãos de segurança, nesses casos, acabou sendo mais eficaz que a própria censura.

Mas os atentados criminosos contra os alternativos, além da censura prévia e das sanções econômicas, não foram os únicos responsáveis pelo desaparecimento dessa imprensa. Precisamos lembrar que os jornais que se opunham à acumulação de capitais passaram a ter muitas dificuldades de circulação nacional, acrescentando-se o fato de que a grande imprensa, com o enfraquecimento do regime, apropriou-se dos temas da imprensa alternativa, contratando ou recontratando os jornalistas que trabalhavam nos alternativos. Somando-se a isso, o papel de relevância na reestruturação política que esses jornais tiveram deixou de ter razão de ser quando os partidos se reorganizaram, e os próprios jornais passaram a ter vínculos partidários mais estreitos. Esses vínculos com partidos e grupos políticos acabaram por separar e dividir os jornalistas e intelectuais, determinando a saída de muitos deles dos jornais. Quando os alternativos passaram a representar um partido ou sindicato, perderam o sentido de alternativos que tiveram durante os governos militares, tornaram-se sectários, e o encanto e a diversidade de que eram porta-voz se ofuscou em nome de um discurso partidário ou sindical ${ }^{6}$.

Assim, a imprensa alternativa que, "nos períodos de maior depressão das esquerdas e intelectuais, funcionava como ponto de encontro espiritual, como pólo virtual de agregação no ambiente hostil e desagregador da ditadura" (KUCINSKI, 1991, p. XXII) acabou

\footnotetext{
${ }^{5}$ Entre os jornais atingidos estão, Pasquim, Coojornal, Repórter, Hora do Povo, Voz da Unidade, Movimento, O Companheiro, O Trabalho, Convergência Socialista, Correio Sindical, Tribuna da Luta Operária, Em Tempo e Jornal do CBA (Comitê Brasileiro de Anistia).

${ }^{6}$ Como exemplo dos alternativos que se vincularam mais estreitamente a partidos políticos temos: Versus e De Fato que acabaram dominados pela prática ideológica; Movimento que tornou-se ‘quase um partido' em fins de 1976, vinculado ao PC do B; Informação de Adelmo Genro Filho, que reproduzia as propisições de Gramsci sobre o papel dos intelectuais; Resistência, publicado em Belém do Pará, que sempre esteve ligado ao PC do B, entre outros.
} 
desaparecendo, coincidindo esse desaparecimento com a reorganização de um regime político menos autoritário.

\section{A aventura alternativa em Porto Alegre}

No Rio Grande do Sul, principalmente em Porto Alegre, foram publicados mais de vinte periódicos alternativos, entre revistas, informativos e jornais. Entre eles: O Protesto, de 1967, ligado ao movimento anarquista. Risco, de 1974, publicado pelos irmãos José Antonio Pinheiro Machado e Ivan Pinheiro Machado. Semanário de Informação Política, publicado em Ijuí e vinculado ao MDB - circulou em 1975. Comunicação, publicado em 1975 pelo Sindicato dos Jornalistas Profissionais de Porto Alegre. Informação, um jornal político publicado por Adelmo Genro em 1976. Triz, publicado em Pelotas em 1976. Neste ano surgiram também Peleia, Lampião e Paralelo, publicados em Porto Alegre. Tição, vinculado ao movimento negro, foi publicado em 1978. Em 1979, foram publicados Lado a Lado e Tchê. Em 1980, Correio da Mulher e, em 1982, Denúncia.

Em meu trabalho de mestrado (ROSA, 2002), analisei a trajetória de três alternativos publicados em Porto Alegre selecionados em função de periodicidade, tempo de circulação e importância no contexto regional. São eles: Exemplar, Pato Macho e Coojornal.

Heterogêneos, com posturas diversas e peculiaridades que vão desde a sua fundação até as estratégias e as formas de crítica ao regime militar, os três periódicos fizeram parte do surto de jornais alternativos que se espalhou pelo país nessa época. Nas próximas páginas, mostrarei brevemente da trajetória de cada um deles.

\section{Exemplar, o desafio da contracultura?}

“A mulher abre a porta e entra em casa: 'Consegui comprar um quilo de carne!' O homem, surpreso, pergunta: 'Deveras? Mas...o que fizeste do teu colar?' A mulher responde: 'Dei como entrada",'

Com o objetivo inicial de divulgar as obras de construção do 'Clube do Professor Gaúcho' em Porto Alegre, financiado pela Incorporadora Raffo Ltda., começou a ser publicado, em 1967, o 'Boletim CPG' - só mais tarde passou a chamar-se Exemplar. Para angariar fundos e conseguir sócios, a Incorporadora decidiu publicar um pequeno jornal

\footnotetext{
${ }^{7}$ Trecho publicado na coluna 'Rio Grande, Em Tempo', no Exemplar número 59.
} 
informativo, contatando alunos do curso de jornalismo. Juarez Fonseca ${ }^{8}$, na época estudante de jornalismo na UFRGS, chamou mais alguns colegas e aceitou a empreitada.

Nos primeiros anos, o jornal teve circulação restrita - distribuído a todos os professores através da listagem da Secretaria Estadual de Educação - sendo que as matérias eram extremamente comedidas, girando em torno das obras de construção do clube. Contudo, aos poucos, isso foi mudando, e as matérias que dariam a tônica ao alternativo começam a fazer parte do universo do jornal, já em 1968. Denúncias de discriminação racial, violência contra indígenas, miséria e fome da população brasileira passam a dar ao jornal um caráter alternativo. As entrelinhas estavam presentes nos textos literários e no humor, principalmente através das HQs - histórias em quadrinhos - de Cláudio Levitan.

A partir de dezembro de 1970, o jornal passou a contar com novos colaboradores, entre eles, Danilo Ucha, Rogério Vaz Mendelski, Cláudio Levitan, Kenny Braga, Roberto Appel, Nelson Souza, Mário Marcos de Souza, Terezinha Turcatto etc. Essa equipe, ao lado de Juarez Fonseca, Ademar Vargas de Freitas, Sérgio Becker, Sonia Azambuja, Carlos Alberto Sampaio, entre outros, passou a escrever matérias continuamente para o jornal. Porém, outras pessoas, entre intelectuais, escritores e jornalistas, enviavam textos esporadicamente, como foi o caso de Caio Fernando Abreu, que também colaborou com o Exemplar.

Com a contribuição dos novos colaboradores, as matérias diversificam-se entre críticas ao imperialismo norte-americano, à situação da América Latina, às prisões efetuadas pelo DOPS, aos crimes do Esquadrão da Morte. Os contos e crônicas de conteúdo libertário e o humor crítico de Cláudio Levitan, questionavam os valores sociais, políticos e a própria posição ou acomodação das pessoas. O jornal ainda divulgava as prisões de jornalistas, publicava entrevistas, como a da feminista Betty Friedman. Encontramos também em suas páginas matérias sobre antipsiquiatria, sobre meio-ambiente, orientalismo, zen-budismo. Alguns elementos da contracultura tornaram-se marcantes no jornal. O Exemplar tornou-se crítico a valores sociais, culturais, educacionais, considerados ultrapassados pelos jovens questionadores da época.

Contudo, com o Clube do Professor concluído, a Incorporadora Raffo não tinha mais porque financiar o Exemplar, e a única saída para que continuasse a ser editado seria tentar a venda nas bancas. Dessa forma, em dezembro de 1972, o jornal deixou de ter circulação dirigida e tentou sobreviver comercialmente. Porém, não conseguiu resistir por muito tempo,

\footnotetext{
${ }^{8}$ Jornalista e crítico musical, na época era estudante de jornalismo e editor do Exemplar.
} 
já que não tinha nenhum apelo comercial e, após seis anos de circulação, deixou de ser editado em novembro de 1973.

As dificuldades com a censura não marcaram a trajetória do jornal, embora as denúncias nas entrelinhas tivessem sido constantes. Para o seu editor, a não existência de problemas com a censura deveu-se ao fato de que os jornalistas que colaboravam com o jornal estavam acostumados ao trabalho na grande imprensa e dela transportaram para o Exemplar a prática de autocensura. No entanto, mesmo com todos esses cuidados, o periódico utilizou brilhantemente o jogo de palavras, as metáforas, as entrelinhas, tornando-se um jornal alternativo profundamente libertário e crítico. Acredito que o fato de praticamente não ter sido vendido nas bancas, já que sua circulação esteve quase toda vinculada ao Clube do Professor Gaúcho, restrita, portanto, influenciou favoravelmente no sentido do jornal não ter sofrido quaisquer tipo de pressões, dentro da lógica multifacetada da censura.

\section{Humor, ironia e irreverência: o Pato ataca o provincianismo}

"O Pato não venceu, foi subjugado, vocês foram os vencedores, só não esqueçam QUE APESAR DE VOCÊS AMANHÃ VAI SER OUTRO DIA. A gente - pelo menos eu e o Ferlauto - tentou, apanhou, mas admitimos o fracasso",

Irreverente, satírico e bem-humorado, surgiu na capital gaúcha, em abril de 1971, o semanário alternativo Pato Macho. Inspirado no Pasquim, o humor debochado da equipe do Pato conquistou o público, e o jornal bateu recorde de vendas logo em seus primeiros números. Reunindo intelectuais e jornalistas famosos em Porto Alegre, tinha como editorchefe Luis Fernando Veríssimo e como editores Cói Lopes de Almeida e Cláudio Ferlauto (mais tarde José Antonio Pinheiro Machado assumiu a função de editor-chefe). Contava ainda com a redação de Carlos Nobre, Sérgio Arnoud e Assis Hoffmann, tendo uma vasta equipe de jornalistas e colaboradores, entre eles, Renato D’Arrigo, Sérgio Alves Rosa, Jefferson Barros e Roberto Pimentel. A idéia de publicar um jornal alternativo na capital gaúcha, segundo Cláudio Ferlauto ${ }^{10}$, já existia desde 1966, contudo, foi somente em 1970, após conseguirem dinheiro para a publicação, que a redação do jornal teve início.

A tônica do Pato Macho foi o humor irreverente que ousava brincar com nomes importantes da sociedade porto-alegrense daquele momento. O lançamento do jornal foi

\footnotetext{
${ }^{9}$ Trecho do jornalista Coi Lopes de Almeida, publicado no Pato Macho de número 04.

${ }^{10}$ Entrevista concedida ao jornal Correio da Manhãa, do Rio de Janeiro (número 23.924, de 13/04/1971, página 46). A matéria foi feita pela Sucursal de Porto Alegre, sendo que na capa saiu uma foto com a equipe do Pato Macho.
} 
precedido por uma grande expectativa da sociedade, e um dos motivos era a identificação com o Pasquim. Essa identificação entre o Pato Macho e o Pasquim atemorizava aqueles que tinham conhecimento da censura sofrida por este último.

O humor da equipe do Pato Macho era feroz quando tratava do provincianismo. O semanário trazia em suas páginas um jogo chamado 'Simandol', definido por Cói Lopes de Almeida como um "fogo que brinca com as pessoas" ", o objetivo do jogo era mostrar o caminho para que os jogadores abandonassem a província. Os nomes de pessoas da sociedade porto-alegrense, através de apelidos ou mesmo referências mais explícitas, podiam ser facilmente identificados. Os provincianos, aos quais o jornal se dirigia, já que o semanário tinha circulação regional, eram definidos como "aqueles que levam tudo as últimas conseqüências, tentando derrubar as novidades em defesa de seus mitos. Assim vamos vivendo na Província a sombra de organizações 'tradicionais'. Um apelido bonito para senis. Nomes e endereços a pedido". Definidos e identificados os provincianos, restou à equipe anunciar o final da decadência:

Agora Porto Alegre está assistindo ao que talvez seja a derradeira tentativa de soltar as amarras. A Rádio Continental, o som do Liverpool, as garotinhas da Independência e, modistica à parte, o Pato Macho. Os provincianos estão grilados, como estariam os decadentes de outras épocas, assustados, agora agarram-se ao que resta de cacaroquete. Embasbacados. (Pato Macho, 1971, n. 1).

A Rádio Continental divulgou o lançamento e fez a publicidade do Pato, sendo, também, uma de suas principais anunciantes. Nas páginas do jornal, eram comuns as referências ao 'judeu' - apelido de Fernando Westfalen, proprietário da rádio e amigo dos jornalistas.

No entanto, não era o fim da decadência; a 'Província', que exultou com os primeiros números do Pato Macho, perdeu o interesse rapidamente, e alguns provincianos, aqueles que eram satirizados pela equipe, explícita ou implicitamente, se inquietaram com o humor do jornal. Tanto que o Pato passou a sofrer censura prévia a partir do terceiro ou quarto número.

A censura que atingiu o Pato foi acionada por Aline Faraco, que era esposa do então reitor da Universidade Federal do Rio Grande do Sul, conhecido como 'doutor Faraco', que, por sua vez, era o médico-cardiologista do general-presidente Emílio Garrastazu Médici. Sentindo-se ofendida pelo jornal e utilizando-se do prestígio que gozava junto ao regime militar, não teve dificuldades em conseguir colocar o jornal na mira da censura prévia.

\footnotetext{
${ }^{11}$ Pato Macho, número 02.
} 
O responsável pelas referências a Aline Faraco foi o jornalista Cói Lopes de Almeida, que já havia sido censurado internamente em outros jornais quando tentava fazer alguma referência à dita senhora, conforme escreveu em sua coluna:

A Senhora: Decididamente não dou sorte com dona Aline Faraco. No tempo do programinha da Zero Hora não conseguia citá-la: Lauro Schirmer encarregava-se de cortar qualquer referência à dita Senhora. Agora, no Pato, que é meio meu, o Luis Fernando Veríssimo curtiu uma de censor. Foi só eu botar Aline no meio do Simandol (o fogo que brinca com as pessoas) pra que o risco viesse em forma de 'pô! Ela é amiga da gente lá em casa, pode dar galho...' Até aí nada de novo, o pior é que em outra referência, o Izidoro, linotipista de Zero Hora, resolveu trocar o $\mathrm{n}$ por c e Aline virou Alice. Agora quero ver se não sai: ALINE. Pronto! Estou vingado. (Pato Macho, 1971, n. 2).

A pequena 'vingança' de Cói acabou por movimentar a censura prévia, de maneira que o jornal precisava da liberação de um censor da Polícia Federal antes de ser impresso. Segundo Luis Fernando Veríssimo e Cláudio Ferlauto, a relação entre a equipe do semanário e o censor foi 'cordial', sendo que os cortes se restringiam às referências à "dona" Aline Faraco. Para Cláudio Ferlauto ${ }^{12}$, "o censor olhava tudo. Olhava, se divertia, ria e dizia assim: 'bom, vamos tirar a dona Aline Faraco...vamos tirar essa menção à dona Aline Faraco...”. Essa atuação censória foi mais uma faceta dentre as muitas facetas que assumiu a censura política do regime militar. Essa foi uma censura pessoal, através da qual, para 'proteger' uma pessoa influente da sociedade, o regime mobilizou a censura da Polícia Federal.

Por fim, aqueles que receberam o semanário com expectativa acabaram por se desinteressar, o humor da equipe não frutificou, e logo o jornal ficou sem anunciantes. Não conseguindo sobreviver das vendas, deixou de ser publicado depois do décimo quinto número. Os gaúchos não conseguiram rir de si mesmos junto com o Pato, o efêmero jornal alternativo que causou alvoroço em Porto Alegre. O "apesar de vocês" - citação da epígrafe dirigia-se, desta vez, não ao regime militar propriamente dito, mas a algumas parcelas da sociedade gaúcha que se inquietaram, sentindo-se ofendidos com o humor da equipe do Pato $^{13}$.

\section{Coojornal: o sonho de fazer um 'jornal de jornalistas'}

"Eu devia ter desconfiado quando você disse que estava tudo sob controle ${ }^{14,}$

\footnotetext{
${ }^{12}$ Entrevista realizada em 20/03/2002.

${ }^{13}$ Os nomes de pessoas conhecidas eram citados diretamente, como no seguinte trecho, do jogo 'Siamandol': "Você saiu na coluna social do Jornal do Comércio. Tá fú. Reconcilie-se com a sociedade sendo igualzinho ao Urbano Garcia. Saia do jogo porque não estamos aqui pra agüentar muquiranas” (Pato Macho, n. 1).

${ }^{14}$ A frase acompanha a figura de dois homens amarrados em uma parede. Humor de Luís Fernando Veríssimo, publicado no Coojornal, número 13.
} 
O sonho de fazer um 'jornal de jornalistas', que publicasse o que a grande imprensa não publicava, que discutisse a situação política e que valorizasse os profissionais do meio jornalístico através de melhoria na remuneração e maior liberdade nas publicações, foram fatores que motivaram um grupo de jornalistas gaúchos a fundar o Coojornal. Publicado na capital gaúcha, ele foi um mensário alternativo que conquistou notoriedade nacional e atraiu para si a repressão do regime militar em pleno início da década de oitenta, os anos ditos de 'abertura democrática', nos quais, oficialmente, não havia mais censura prévia à imprensa.

A circulação do Coojornal esteve vinculada à criação da Cooperativa dos Jornalistas de Porto Alegre Ltda. (Coojornal), fundada em agosto de 1974. Foi a primeira cooperativa de jornalistas do país e, devido ao seu sucesso, posteriormente, a idéia estendeu-se a outros estados. O sucesso da Cooperativa gaúcha incentivou a publicação de um boletim, o Coojornal, que começou a circular em 1975 e, em 1976, transformou-se em jornal. Um jornal publicado mensalmente, alternativo, ousado, político, com circulação nacional, que sobreviveu até 1983 quando, por um conjunto de razões, deixou de circular.

Nas páginas do Coojornal, encontramos denúncias sistemáticas e abertas de censura à imprensa, críticas aos equívocos da equipe econômica, aos efeitos devastadores do milagre econômico, defesa da anistia, de eleições diretas, publicações de documentos inéditos sobre a Guerrilha do Araguaia e de listas de cassados durante os anos de vigência do regime militar. Também encontramos um humor político, implacável, feroz e, muitas vezes, amargo. As críticas sistemáticas a alguns órgãos da grande imprensa, tão coniventes com a situação política vivenciada no país naquele momento, como o Sistema Globo de Telecomunicações e sua 'afiliada', a RBS, também faziam parte dos assuntos mais veiculados no periódico.

Os primeiros problemas do Coojornal com a repressão surgiram em 1977. A publicação de uma matéria sobre o número total de parlamentares cassados pelo regime militar - "4.682 é o número de cassados em 13 anos de revolução" -, ampla e com chamada de capa e foto do deputado do MDB, Alencar Furtado, na época um recém cassado, provocou a ira do regime. Esse foi o primeiro levantamento sobre os cassados nos anos de governos militares.

Foi a gota d'água para a repressão agir. Imediatamente, agentes da Polícia Federal gaúcha visitaram anunciantes do Coojornal, identificando o jornal com a esquerda e com o comunismo, 'solicitando' aos anunciantes que retirassem seus anúncios e rompessem seus contratos com a Cooperativa. A ‘solicitação' foi acompanhada da ameaça de 'dificuldades futuras', caso esses não atendessem ao 'pedido' dos agentes da Polícia Federal. O resultado 
foi imediato, na edição seguinte, a maioria dos anunciantes suspendeu seus anúncios, rompendo contratos de longo prazo (entre os anunciantes que suspenderam seus contratos, empresas de grande porte como Gerdau, Samrig, GBOEX e Olvebra, entre outras). Após esse episódio, apenas três cooperativas gaúchas mantiveram seus anúncios.

Contudo, as grandes reportagens que versavam sobre a história recente do país tornaram-se marcas registradas do Coojornal e continuaram a ser publicadas. Entrevistas com políticos como Leonel Brizola, nos Estados Unidos, entrevista com Luís Carlos Prestes, com Pedro Simon, matérias sobre militares conspiradores, como o general Olimpyo Mourão Filho, entre outras, faziam parte do jornal. Matérias que provocavam a repressão ao jornal em plena 'abertura política'.

Uma matéria sobre os Tupamaros causou novas dificuldades, em 1979, quando o jornal foi identificado como subversivo, ao ser acusado pelo SNI de ter como um de seus financiadores o grupo conhecido como 'Tupamaros', que lutaram pelo fim do regime autoritário no Uruguai.

Em fevereiro de 1980, o Coojornal publicou uma matéria longa e inédita sobre a Guerrilha no Brasil, matéria que teve por base relatórios secretos (até então) do Exército, sob o título de capa: Os Relatórios do Exército sobre a Guerrilha. Os jornalistas compraram os relatórios do cabo de Exército Carlos Mer Echevarria. O conteúdo dos relatórios descrevia a perseguição ao grupo de Carlos Lamarca, no Vale do Ribeira, em 1970, operação denominada de 'Registro', pelos militares. Nos relatórios, os militares faziam uma avaliação da operação frustrada. Também descreviam a operação de 1971, chamada pelo exército de 'Operação Pejussara', que foi bem sucedida na caça a Lamarca.

A resposta da repressão foi um golpe profundo no Coojornal e na Coojornal (a cooperativa), já enfraquecida pelas disputas internas. Os jornalistas foram processados pela divulgação dos documentos secretos e por prevaricação. Além do processo, que resultou em prisões de jornalistas, a repressão novamente partiu para a pressão sobre os anunciantes e, desta vez, bombas foram jogadas em bancas que vendiam o jornal.

Segundo Elmar Bones ${ }^{15}$, tudo não passou de uma farsa do próprio regime, o cabo que entregou os documentos foi incumbido pelos seus superiores desse 'trabalho'. A idéia era justamente poder cavar uma brecha para processar e fechar o jornal. Bones diz que, anos mais tarde, encontrou o cabo que confirmou essa versão.

\footnotetext{
${ }^{15}$ Depoimento gravado em VHS, disponível no 'Acervo de Luta contra a Ditadura' no Memorial Histórico do Rio Grande do Sul.
} 
O Inquérito policial-militar contra os jornalistas arrastou-se por três anos, resultando, inclusive, na prisão, por alguns dias, de alguns deles. Somando-se a esse episódio, a crise financeira e as divergências internas na direção da cooperativa, o Coojornal não resistiu e acabou deixando de circular em 1983.

\section{Considerações finais}

Tendo em comum a oposição a uma ordem autoritária, as proximidades de linguagem e, na grande maioria dos casos, um tempo curto de circulação, os jornais alternativos durante o regime militar enriqueceram as estratégias de resistência e a própria linguagem jornalística, cada um a sua maneira e dentro de suas peculiaridades. Heterogêneos, com diferentes propostas e objetivos, muito embora os colaboradores e jornalistas fossem os mesmos em mais de um jornal alternativo, esses periódicos aglutinaram jornalistas, intelectuais, políticos, artistas, estudantes que encontravam neles uma forma de expressarem sua idéias, críticas e mesmo angústias. Nesse sentido, a imprensa alternativa pode ser entendida, também, como "uma forma de enfrentar a solidão, a atomização e o isolamento de uma situação autoritária" (FOX, 1983, p. 34). Apesar de limitados pela repressão, esses periódicos conseguiram sustentar um discurso de oposição ao discurso oficial sustentado pelo regime militar.

Entretanto, mesmo contribuindo efetivamente para desmascarar a violência da ditadura e suas contradições, temos de reconhecer que os jornalistas alternativos não foram 'mártires' na luta contra o regime militar. Digo isso porque, se existiu uma imprensa alternativa durante esse período e se esses jornais puderam testar os limites e desafiar os militares e os setores mais conservadores da sociedade, mesmo de forma efêmera em sua duração, de certo modo, isso foi possível porque havia uma brecha, tênue, na maioria das vezes, nas quais jornalistas e intelectuais podiam expressar seu descontentamento, suas visões de mundo. Essa brecha foi encontrada nas constantes tentativas de legitimação da ditadura, que tolerou, apesar das coações, prisões e intimidações, a existência da imprensa alternativa. Com isso, os alternativos testaram as brechas do regime, forçaram seus limites, jogaram com a censura e a repressão e, algumas vezes, perderam muito. Se existiu algum heroísmo por parte das pessoas que produziam esses jornais, esse heroísmo esteve na persistência em denunciar, criticar e se opor a todo um aparato repressivo, seja no âmbito político, cultural, social, moral, etc. Se um jornal era fechado, jornalistas, colaboradores, cartunistas, estavam prontos a se vincularem a outros projetos semelhantes e mesmo iniciar outro jornal. 


\section{Referências}

AQUINO, Maria Aparecida de. Censura, Imprensa, Estado Autoritário. São Paulo: EDUSC, 1999.

ARAÚJO, Maria Paula Nascimento. Política, esquerda e imprensa alternativa no Brasil dos anos 70: objetos e fontes históricas. Rio de Janeiro: IFCS/UFRJ, 1999.

BRAGA, José Luiz. O Pasquim e os anos 70: mais pra epa que pra oba. Brasília: UnB, 1991.

CAPARELLI, Sérgio. Comunicação de massa sem massa. São Paulo: Cortez, 1982.

CHINEM, Rivaldo. Imprensa alternativa: jornalismo de oposição e inovação. São Paulo: Ática, 1995.

FESTA, Regina. Comunicação popular e alternativa no Brasil. São Paulo: Paulinas, 1988.

FOX, Elizabeth. Comunicação e Política. Rio de Janeiro: Paz e Terra, 1983.

MICOLLIS, Leila. Catálogo de Imprensa Alternativa. Rio de Janeiro: Rio Arte, 1986.

KUCINSKI, Bernardo. Jornalistas e revolucionários nos tempos da imprensa alternativa. São Paulo: Página Aberta, 1991.

KUCINSKI, Bernardo. A síndrome da antena parabólica ética no jornalismo brasileiro. São Paulo: Fundação Perseu Abramo, 1999.

REGO, Norma Pereira. Pasquim, gargalhantes pelejas. Rio de Janeiro: Relume-Dumará, 1996.

ROSA, Susel Oliveira. da. Exemplar, Pato macho e Coojornal: trajetórias alternativas. 2002. Dissertação (Mestrado em História) - Pontifícia Universidade Católica do Rio Grande do Sul, Porto Alegre, 2002.

UCHA, Danilo. História do Coojornal. In: O poder da imprensa alternativa pós-64: histórico e desdobramentos. Rio de Janeiro: RIOARTE, 1985. 